\title{
Socioeconomic inequalities in non- communicable disease risk factors in Botswana: a cross-sectional study
}

\author{
Mpho Keetile*, Kannan Navaneetham, Gobopamang Letamo and Serai Daniel Rakgoasi
}

\begin{abstract}
Background: The debate on socioeconomic inequalities in health dominates the research and policy agenda of many countries. The prevalence of non-communicable diseases (NCDs) is on the rise in recent years in Botswana. As a prevention and policy effort, the study provided an empirical evidence on socioeconomic inequalities in NCD risk factors in Botswana.

Methods: Data used in this study was derived from a cross sectional survey on chronic non communicable diseases in Botswana conducted in 2016. The survey adopted a multistage sampling design and a sample of 1178 participants (males and females) aged 15 years and above was selected in both urban and rural areas of Botswana. The inequality analysis was conducted employing decomposition analysis using ADePT software version 6. Logistic regression models were used to show the association between NCD risk factors and socioeconomic status using SPSS version 25.

Results: Concentration indices showed that poor physical activity $(\mathrm{Cl}=0.0546)$, alcohol consumption $(\mathrm{Cl}=0.1859)$ and overweight/obesity $(\mathrm{Cl}=0.038)$ were more concentrated among the non-poor while daily smoking $(\mathrm{Cl}=-0.0308)$ and poor fruit/vegetable consumption $(\mathrm{Cl}=-0.1909)$ were more concentrated among the poor. Wealth status was observed to be the leading contributor to socioeconomic inequality for daily smoking, poor fruit/vegetable consumption, overweight/obesity and poor physical activity. Education was the leading contributor to socioeconomic inequality for alcohol consumption.

Conclusions: Findings in this study indicate the need for concerted differential efforts to address the needs of the poor and non-poor in order to reduce NCD risk factor inequalities.
\end{abstract}

Keywords: Inequalities, NCDs, Risk factors, Botswana, Decomposition analysis

\section{Background}

It has been observed across the world that there are inequalities in health, no matter what measure of socioeconomic status has been used [1-3]. These inequalities have been found to be common among populations at both national and subnational levels. As a result understanding the impacts of social, economic and demographic factors on health is an important policy challenge. In some countries it has been observed that the burden of most non-communicable disease (NCD) risk factors is relatively higher amongst disadvantaged and marginalised

\footnotetext{
* Correspondence: mphokeet@yahoo.com

Department of Population Studies, University of Botswana, Gaborone,
} Botswana

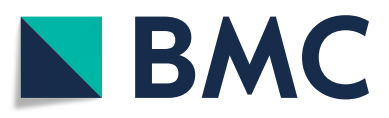

(๑) The Author(s). 2019 Open Access This article is distributed under the terms of the Creative Commons Attribution 4.0 International License (http://creativecommons.org/licenses/by/4.0/), which permits unrestricted use, distribution, and

reproduction in any medium, provided you give appropriate credit to the original author(s) and the source, provide a link to the Creative Commons license, and indicate if changes were made. The Creative Commons Public Domain Dedication waiver (http://creativecommons.org/publicdomain/zero/1.0/) applies to the data made available in this article, unless otherwise stated. individuals and groups, compared with those with higher socioeconomic status (SES) [1,2]. As a consequence of this, there is well-documented evidence of inverse health and wealth gradient in many contexts $[3,4]$. In some contexts the gradient between wealth and health has been found to be positive, while in other contexts it is negative [5].

Much of work on socioeconomic inequalities in NCD risk factors in high-income countries (HIC) has shown that the poor are more likely to report all NCD risk factors [6]. On the other hand studies on socioeconomic inequalities in low and middle-income countries (LMICs) regarding the interaction between SES and health are relatively scarce [7]. Few available studies from LMICs show 
that poor people are more likely to report smoking, poor fruit/vegetable consumption and alcohol consumption [8-12] and that overweight/obesity is more likely to be observed among the non-poor [13-17]. Available evidence also shows that there is no significant association between SES and poor physical activity [18].

Socioeconomic and behavioural factors have been recognized as some of the main explanatory variables for health inequalities $[19,20]$. A significant part of socioeconomic differences in health have been linked to various health behaviours [21, 22]. The adoption of risky health behaviours have been observed to shift from people of higher to lower SES as countries develop more with higher socioeconomic groups adopting new behaviours early and discarding them rather quickly upon learning of the related health consequences [23]. As higher socioeconomic groups discard these risky behaviours, lower socioeconomic groups are more inclined to take up these behaviours later [23].

In Botswana NCD risk factor surveilaence has been ongoing in recent times. However, there is little evidence of the association between SES and the prevalence of NCD risk factors. It is important to undertsand socioeconomic differences in NCD risk factors in order to identify which SES groups are most affected. It has been observed that NCD risk factors have great variation in their distribution among different socioeconomic groups within societies, and their distribution patterns are quickly changing and they are taking diverse patterns within various societies [22-24]. Whereas there is some literature on social determinants of NCDs, little is known about the corresponding social determinants of NCD risk factors. Moreover, the majority of studies addressing the question of inequalities in NCD risk factors have often used conventional regression models [21-23] which are not the best-suited to estimate social inequalities in NCD risk factors or unveil their determinants. Consequently, more insight into inequalities in NCD risk factors is important for policy purposes and for providing an understanding of the factors that are likely to contribute to socioeconomic inequalities in Botswana. It is against this background, that this study aims to assess socioeconomic inequalities in NCD risk factors. We used decomposition analysis to determine the contribution of a broad range of social determinants on the NCD risk factors inequalities. This study would contribute to the enhanced understanding of the extent of NCD risk factors burden and their socioeconomic inequalities in Botswana.

\section{Methods}

\section{Data}

The study used secondary data derived from a cross sectional survey. The survey employed stratified multistage probability sampling technique to select respondents in three cities and towns, fifteen urban villages and fifteen rural areas across Botswana (refer to Additional file 1 methodology file). The survey was carried out in March 2016. The survey collected information on NCDs and their risk factors. The targeted sample size for the survey was 1280 from which 1178 respondents were successfully interviewed, yielding a response rate of $92 \%$.

\section{Definitions and measurement of variables}

Information on NCD risk factors was collected through self-reports. The survey questionnaire was adapted from the WHO STEPS and WHO Study on Global Ageing and Adult Health (SAGE) instruments (Additional file 2 questionnaire). Respondents were asked questions on tobacco use, alcohol consumption, physical activity and fruit and vegetable consumption. All NCD risk factors were dichotomised [24] to indicate whether respondents reported or did not report any NCD risk factors. For tobacco use respondents were asked whether they currently smoke tobacco products, yes $=1$ and no $=0$. Alcohol consumption was measured based on the intensity of alcohol consumed in the past 30 days. Respondents were asked (only those who reported to have consumed alcohol in the past 30 days) about the number of standard alcohol drinks they had each day in the past 7 days and if those who reported to have had three or more drinks per day (of approximately $60 \mathrm{~g}$ alcoho 1 ) were considered to have exercisive drinking $=1$ and $0=$ otherwise.

An adapted version of the WHO STEPS questionnaire for adults was used to assess participants' self-reported physical activity [25]. The questionnaire assessed physical activity done in the past 7 days in the domains of work and walking (includes at work and at home, walking to travel from place to place, and any other walking for recreation, sport, exercise, or leisure). The time spent on moderate and vigorous intensity activities was estimated in terms of frequency (days per week) and duration (minutes per day) taken in each of the two physical activity domains [25]. Poor physical activity variable was computed as daily minutes (min/day) of physical activity scores in the work and walking domains. The variable was computed by summing up the time spent ( $\mathrm{min} /$ day) in moderate-intensity and vigorous-intensity activities across the two domains such that if respondents took $>10$ minutes bouts of physical activity per day and $<10$ minutess bouts of physical activity per day they were considered physical active $=0$ and to have poor physical activity $=1$, respectively.Poor fruit and vegetables consumption was created when an individual reported daily consumption of less than the recommended 5 servings of fruit and vegetables. Respondents reported the number of servings for fruits/vegetables they had in a typical day, and if the servings were less than 5 in 
a day, they were considered to be having poor fruit/vegetable consumption [26].

The NCD survey collected anthropometric information on height in meters $(\mathrm{m})$ and weight in kilograms $(\mathrm{kg})$ as per WHO guidelines [27]. Body Mass Index (BMI) was used to classify overweight/obesity. BMI was derived from weight and height: weight $(\mathrm{kg}) /$ (height $(\mathrm{m}) \mathrm{x}$ height $(\mathrm{m})$ ) [1]. The Charder MS7301 $250 \mathrm{Kg}$ digital scale and the Muac measuring tape were used for anthropometric measurements. Weight of respondents was measured, to the nearest $0.1 \mathrm{~kg}$, while their height was measured in metres. BMI was categorized into: underweight $(\mathrm{BMI}<18.5 \mathrm{~kg} /$ $\left.\mathrm{m}^{2}\right)$, normal weight $\left(18.5 \leq \mathrm{BMI}<25 \mathrm{~kg} / \mathrm{m}^{2}\right)$, overweight $\left(25 \leq \mathrm{BMI}<30 \mathrm{~kg} / \mathrm{m}^{2}\right)$ and obese $\left(\mathrm{BMI} \geq 30 \mathrm{~kg} / \mathrm{m}^{2}\right)$ [1]. Overweight and obese were used to create a binary outcome variable which was coded as: being overweight/obese $\left(B M I \geq 25 \mathrm{~kg} / \mathrm{m}^{2}\right)=1$; not overweight/ obese $=0\left(\mathrm{BMI}<25 \mathrm{~kg} / \mathrm{m}^{2}\right)$.

A wealth index (WI) was constructed and used as a measure of socioeconomic status (SES). It is a composite measure, constructed from the indicators of ownership of consumer durables, housing characteristics, and access to public services. Information on a wide range of durable assets was collected (e. g. ownership of telephone, car, refrigerator, television), housing characteristics (e. g. material of dwelling floor and roof, main cooking fuel), access to basic services (e. g. electricity supply, source of drinking water, sanitation facilities) and ownership of livestock (e.g. cattle, goats, sheep, horses, chickens). Further to the collection of information on durable assets, information on land and livestock ownership was collected. Principal component analysis was employed to derive the wealth index variable, which had five categories from the 1 st to the 5 th quintile (poorest to richest).

\section{Control variables}

Socio-demographic factors such as age, sex, marital status, work status, residence and education were used as controls for the analysis. These variables were conceptualized to have an association with NCD risk factors on the basis of the review of literature. Therefore to control for their likely association with NCD risk factors, they were included in the combined effects model, so that the association between the wealth status and NCD risk factors becomes isolated and discernible.

\section{Statistical analysis}

Logistic regression analysis was used to assess the association between socioeconomic variables and NCD risk factors using SPSS version 25. Results of logistic regression models were presented as adjusted odds ratios (AOR) together with their 95\% confidence intervals.

Analysis of socioeconomic inequalities in NCD risk factors was done using ADePT software (version 6). The socioeconomic inequalities were derived using concentration curves and concentration indices. Concentration curves were used to plot the cumulative share of the NCD risk factor variables against the cumulative share of the wealth status variable. In calculating the cumulative percentages, wealth status was ranked from lowest to highest quintile. If any NCD risk factor was equally distributed, the curve would be running from the bottom left hand corner to the top right-hand corner (a $45^{\circ}$ line). This is known as the line of equality. Contrarily, if the share of NCD risk factor was low among the poor, the concentration curve would lie below the line of equality [28-30]. The further the curve is from the diagonal, the greater the degree of inequality. The first case of socioeconomic inequality is the case in which individuals with high SES have a positive value of concentration index., while the second case, where the curve is above the diagonal line, is known as socioeconomic inequality which disadvantages the individuals of lower SES and the value of the concentration index is negative [31].

For the concentration index the value of the NCD risk factor assigned to each individual was taken to be a function of the socioeconomic category to which the individual belongs. The value of the concentration index ranges between -1 to +1 . The index is 0 if there is no socioeconomic related inequality. The achievement index was also used with the concentration index to reflect the average level of NCD risk factors and the inequality in NCD risk factors between the poor and the better-off. It is the weighted average of the NCD risk factors of the various people in the sample, in which higher weights are attached to poorer people than to better-off people [29]. The larger value of the index is considered as higher health disachievment to one group of population than others group. (Refer to Additional file 3 for the decomposition analysis equation).

\section{Results \\ Sample characteristics}

Table 1 presents the characteristics of the study population. The study population constituted a high proportion of females $(69.1 \%)$ than males (30.9\%). The sample age distribution suggests a relatively young population, with over half (59\%) of the sample being less than 39 years of age, and almost three quarters (73.5\%) being less than fifty years of age. More than two fifths $(45.4 \%)$ of the population resided in urban villages; just under a third $(30.2 \%)$ resided in cities or towns while a quarter $(24.5 \%)$ resided in rural settlements. Almost three quarters (73.8\%) of respondents were never married; over a third (35.5\%) had primary education or less; over a quarter (27.2\%) had junior secondary education while just under a fifth had senior secondary education (17.3\%) and tertiary education and over (19.9\%). Close to two fifths 
Table 1 Socioeconomic characteristics of the study population (N=1178) -NCD survey, 2016

\begin{tabular}{|c|c|c|}
\hline Variable & Percentage (\%) & Frequency $(N)$ \\
\hline \multicolumn{3}{|l|}{ Sex } \\
\hline Male & 30.9 & 364 \\
\hline Female & 69.1 & 813 \\
\hline Missing & & 1 \\
\hline \multicolumn{3}{|l|}{ Age in years } \\
\hline$<24$ & 26.4 & 270 \\
\hline $25-34$ & 29.5 & 302 \\
\hline $35-44$ & 19.2 & 196 \\
\hline $45-54$ & 12.7 & 130 \\
\hline $55-64$ & 7.3 & 75 \\
\hline $65+$ years & 4.9 & 50 \\
\hline Missing & & 155 \\
\hline \multicolumn{3}{|l|}{ Locality Type } \\
\hline Cities/Towns & 30.2 & 355 \\
\hline Urban Villages & 45.4 & 534 \\
\hline Rural Settlements & 24.5 & 288 \\
\hline Missing & & 1 \\
\hline \multicolumn{3}{|l|}{ Marital Status } \\
\hline Never Married & 73.8 & 864 \\
\hline Currently married & 17 & 199 \\
\hline Formerly married & 9.2 & 108 \\
\hline Missing & & 7 \\
\hline \multicolumn{3}{|l|}{$\begin{array}{l}\text { Highest Level of } \\
\text { Education Attained }\end{array}$} \\
\hline Primary or Less & 35.5 & 410 \\
\hline Junior Secondary & 27.2 & 314 \\
\hline Senior Secondary & 17.3 & 200 \\
\hline Tertiary \& Over & 19.9 & 230 \\
\hline Missing & & 24 \\
\hline \multicolumn{3}{|l|}{$\begin{array}{l}\text { Work Status in } \\
\text { past } 12 \text { months }\end{array}$} \\
\hline Public Sector & 10.5 & 122 \\
\hline Private Sector & 15.7 & 182 \\
\hline Self Employed & 11.2 & 130 \\
\hline Not Employed & 37.5 & 436 \\
\hline Homemaker-Student & 18.8 & 218 \\
\hline Retired-Other & 6.4 & 74 \\
\hline Missing & & 16 \\
\hline \multicolumn{3}{|l|}{ Wealth status } \\
\hline Lowest & 19.9 & 234 \\
\hline Second & 20.1 & 237 \\
\hline Middle & 19.9 & 235 \\
\hline Fourth & 20.1 & 237 \\
\hline Highest & 19.9 & 235 \\
\hline
\end{tabular}

Table 1 Socioeconomic characteristics of the study population $(N=1178)$-NCD survey, 2016 (Continued)

\begin{tabular}{lll}
\hline Variable & Percentage $(\%)$ & Frequency $(N)$ \\
\hline Missing & - \\
Overall & 1178 \\
\hline
\end{tabular}

(37.5\%) of respondents were not employed; while over a quarter were employed in either the public $(10.5 \%)$ or private sector (15.7\%). Just over one in every ten $(11.2 \%)$ were self-employed, while close to a fifth $(18.8 \%)$ were either home makers or students; while under a tenth (6.4\%) were retired from work.

\section{Prevalence of NCD risk factors}

Figure 1 shows prevalence of NCD risk factors in the study population. Poor fruit and vegetable consumption was found to be the most prevalent NCD risk factor at $82.5 \%$. Similarly poor physical activity $(48.9 \%)$ and overweight/obesity (41.3\%) were also found to be high. On the other hand it was seen that prevalence of smoking $(11.5 \%)$ and alcohol consumption (17.3\%) were relatively low in the population compared to other risk factors.

Table 2 presents the adjusted odds ratios (AORs) derived from logistic regression model for the risk factors among SES strata controlling for other demographic and social characteristics. The results indicate that the odds of smoking (AOR $=2.85$, C.I. $=1.12-7.27)$, poor fruit and vegetable consumption $(\mathrm{AOR}=2.30$, C.I. $=1.06-5.86)$ and poor physical activity $(\mathrm{AOR}=1.73$, C.I. $=1.00-2.99)$ were significantly high among people with poor SES compared to highest SES. On the other hand,no significant differences observed between poor and non-poor for alcohol consumption and overweight/obesity.

\section{Inequalities in NCDs risk factors}

Results of the inequality measures of concentration indices $(\mathrm{CI})$ and the standard achievement indices for NCD risk factors are presented in Table 3. When the concentration index is high, the achievement index will be low and vice versa [29]. The positive CI value of 0.1859 for alcohol consumption indicates skewness towards the non-poor population and the corresponding standard achievement index is low, while the low positive CI values of 0.0546 and 0.0308 shows that poor physical activity and overweight/obesity respectively, are close to the line of equality but seems to be concentrated among the non-poor. The negative CI values of -0.0308 for daily smoking and -0.1909 for poor fruit and vegetable consumption indicate skewness towards the poor population. These negative CI values (for poor fruit and vegetable consumption and smoking) are also accompanied by high corresponding standard achievement indices. 


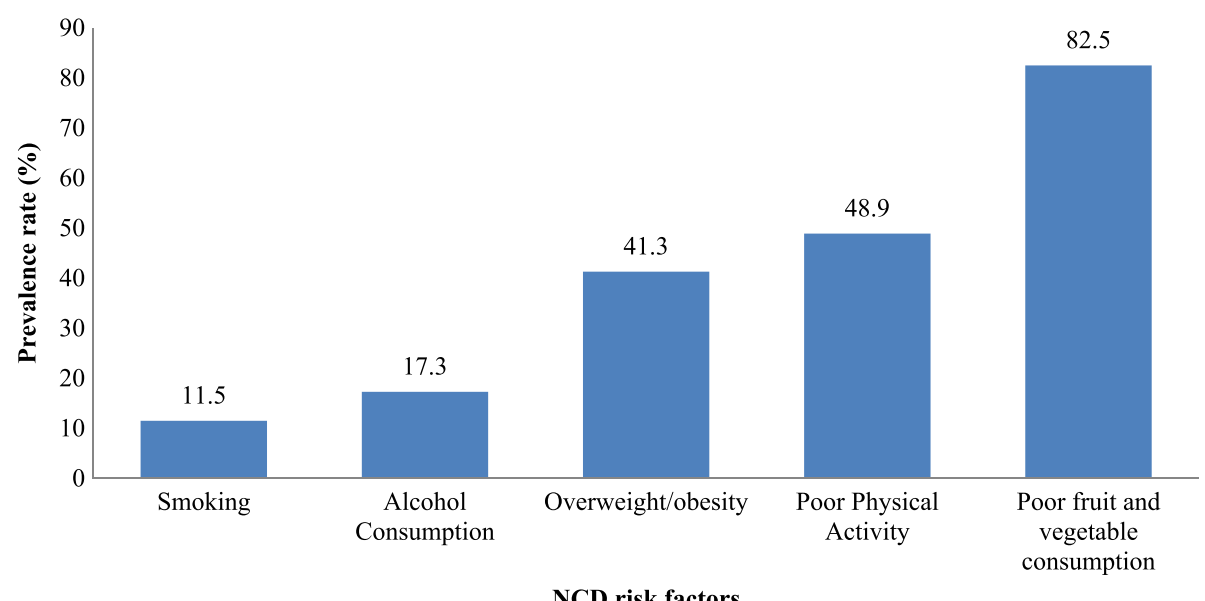

Fig. 1 Prevalence of NCD risk factors in Botswana ( $N=1178)-$ NCD survey, 2016

Figure 2 shows the concentration curves plotting the cumulative share of selected NCD risk factors against the proportional cumulative share of wealth index (SES) score of individuals. The curve for alcohol consumption lies below the line of equality which confirms that alcohol consumption was more concentrated among the nonpoor. Concentration curves for physical activity and overweight/obesity almost overlap with the line of equality showing that socioeconomic differences in physical activity and overweight/obesity were negligible but somewhat skewed towards the non-poor. This indicates that these two risk factors were skewed towards the non-poor although the inequality is relatively small. The curves for smoking and poor fruit and vegetable consumption were above the line of inequality showing concentration among the poor.

\section{Decomposing inequalities in risk factors for NCDs}

Figure 3 presents a contribution of the selected socioeconomic determinants on the overall concentration index. The height of the bar corresponds to the contribution of socioeconomic factor (e.g. education, wealth status, sex, residence and work status) in explaining the observed inequality. Inequalities for daily smoking, poor physical activity, overweight/obesity and poor fruit and vegetable consumption were explained by differences in wealth status. The contribution of wealth status to daily smoking, poor physical activity and poor fruit and vegetable was negative while for overweight/obesity it was positive. Education was the leading contributor to socioeconomic differences for alcohol consumption and its contribution was positive indicating that alcohol consumption was high among the educated group.

\section{Discussion}

Understanding inequalities in NCD risk factors from the Botswana perspective is particularly relevant since the social and public health landscape may blur any impressions of inqualities. For example the universal primary health care coverage and Botswana's middle income status may suggest that there are no inequalities in health. Meanwhile, it has been observed in this study that alcohol consumption, overweight/obesity and poor physical activity were more concentrated among the non-poor while smoking and poor fruit and vegetable consumption were more concentrated among the poor. This corroborates results from other studies conducted in both developed and developing countries [31-33].

In the context of Botswana the concentration of alcohol among the non-poor is expected. This is because

Table 2 Odds ratios and 95\% confidence intervals from logistic regressions of NCD risk factors among SES groups-NCD survey, 2016

\begin{tabular}{llllll}
\hline SES/Wealth status & $\begin{array}{l}\text { Smoking } \\
\text { AOR Cl }\end{array}$ & $\begin{array}{l}\text { Alcohol consumption } \\
\text { AOR Cl }\end{array}$ & $\begin{array}{l}\text { Poor fruit and vegetables } \\
\text { AOR Cl }\end{array}$ & $\begin{array}{l}\text { Poor physical activity } \\
\text { AOR Cl }\end{array}$ & $\begin{array}{l}\text { Overweight/obesity } \\
\text { AOR Cl }\end{array}$ \\
\hline Lowest & $2.85^{\mathrm{a}}(1.12-7.27)$ & $0.92(0.30-2.82)$ & $2.30^{\mathrm{a}}(1.06-5.86)$ & $1.73^{\mathrm{a}}(1.00-2.99)$ & $1.03(0.64-1.68)$ \\
Second & $1.37(0.55-3.45)$ & $1.59(0.56-4.50$ & $1.91^{\mathrm{a}}(1.01-4.01)$ & $1.62^{\mathrm{a}}(1.00-2.67)$ & $1.12(0.68-1.85)$ \\
Middle & $1.09(0.45-2.66)$ & $0.76(0.30-2.82)$ & $1.74^{\mathrm{a}}(1.02-3.36)$ & $1.38(0.86-2.21)$ & $1.20(0.71-2.01)$ \\
Fourth & $1.04(0.44-2.47)$ & $2.27^{\mathrm{a}}(1.53-5.40)$ & $1.43(0.81-2.55)$ & $1.44^{\mathrm{a}}(1.02-2.20)$ & $1.53(0.87-2.69)$ \\
Highest & 1.00 & 1.00 & 1.00 & 1.00 & 1.00 \\
\hline
\end{tabular}

Note: AOR Adjusted Odd Ratios, Cl Confidence Intervals, ${ }^{a}$ statistically significant at 5\% level. Adjusted for sex, age, education, work status, marital status and residence. $N=1177$ 
Table 3 Concentration indices showing inequalities in risk factors for NCDs in Botswana-NCD survey, 2016

\begin{tabular}{llll}
\hline NCD Risk Factors & Concentration Index $(C l)$ & $95 \%$ Confidence Interval & Standard Achievement Index \\
\hline Poor physical activity & 0.0546 & $(0.0251,0.1231)$ & 1.5069 \\
Alcohol concumption & 0.1859 & $(0.1103,0.4150)$ & 0.1451 \\
Daily smoking & -0.0308 & $(-0.1540,-0.0621)$ & 0.0863 \\
Poor fruit and vegetable consumption & -0.1909 & $(-0.2112,-0.023)$ & 0.1126 \\
Overweight/obesity & 0.0308 & $(0.0123,0.3010)$ & 1.303 \\
\hline
\end{tabular}

consumption of alcohol (especially commercial beverages) has been seen as a symbol of high SES [34]. Consequently, the poor often consume low-cost, homemade sorghum beer; while the non-poor usually take commercial beverages [33-35]. Evidence from study also corroborates some cross-sectional studies which have supported a positive relationship between SES and alcohol use, showing that individuals with higher SES engage in more frequent and heavier drinking of commercial beverages [36-38]. Although people with high SES have been found to consume greater amounts of alcohol compared with people with lower SES, the latter group seems to bear a

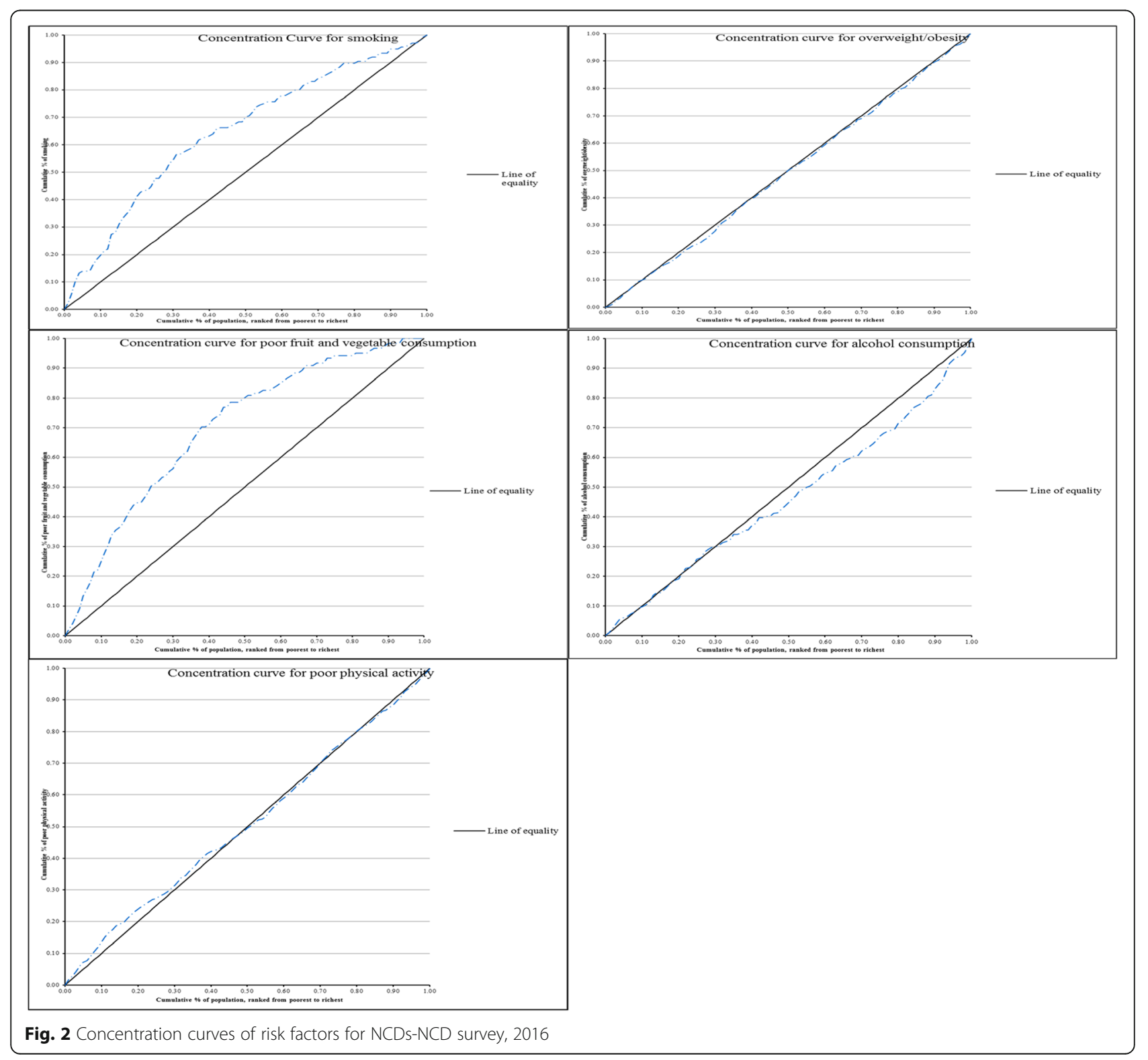


H1:Daily smoking

H2:Alcohol consumption

$\mathrm{H} 3$ :Poor fruit and vegetable consumption

$\mathrm{H} 4$ :Overweight and obesity

H5:Poor physical activity

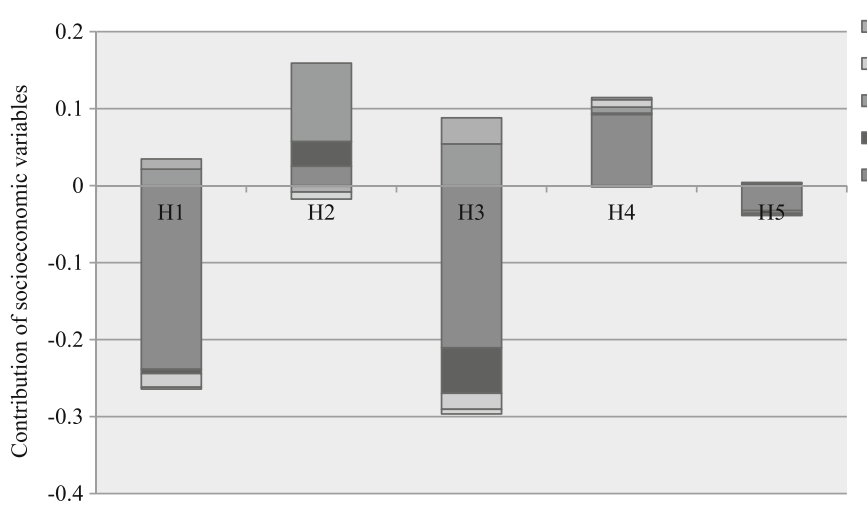

$\square$ Residence

WrkStatus

$\square$ sex

$\square$ Education

MaritulStatus

๑wealthm1

disproportionate burden of negative alcohol-related consequences [36, 38].

The concentration curves for poor physical activity and overweight/obesity almost overlapped with the line of equality showing that although these risk factors were concentrated among the non-poor, the degree of inequality was small. The low inequality for poor physical activity and overweight/obesity may be explained by behavioural shift from traditionally active lifestyles to more industrialized and sedentary lifestyles among both the poor and non-poor in Botswana. Moreover, Botswana has experienced economic development and the consequent increases in income and the availability of inexpensive, high-calories foods, and low physical activity may have led to overweight/obesity which disproportionately affects the upper and middle classes to becoming widespread among the poor [35].

Concentration curves for daily smoking and poor fruit and vegetable consumption were above the line of equality suggesting that these two risk factors were more concentrated among the poor. This finding corroborates multivariate results which have also shown that smoking and poor fruit and vegetable consumption were more likely to be found among the poor. There is research evidence to suggest that purchasing and consumption of unhealthy diets, in particular, eating fewer fruits and vegetables, is strongly patterned by socioeconomic status (SES) [38-40]. It is suggested that poor fruit and vegetable consumption is more concentrated among the poor perhaps because the poor may not afford fruits and vegetables $[40,41]$. Moreover, individuals of lower SES generally tend to have less healthy diets than those of higher SES [41].
As in previous studies it was found that smoking was disproportionately high among the poor [42-44]. It has been argued that due to high smoking rates among poor, they end up suffering more from diseases caused by smoking than do non-poor [43-46]. In Botswana the observed smoking inequality is rooted in many inequities ${ }^{33}$. This is because the poor have the least information about the health hazards of smoking, the fewest resources and social supports, and often the least access to services to help them quit. On top of that, the tobacco industry has a long history of targeting low SES individuals and communities.

Decomposition analysis showed that inequalities in alcohol consumption, poor physical activity and overweight/obesity can be explained by inequalities in education and wealth status. But the effects of contribution of education and wealth status to these three outcomes were different. This corroborates some studies which have pointed out education and wealth status as key determinants of health in developing countries [7, 16, 20, 23]. Similalry, inequalities in alcohol consumption were explained by inequalities in education, while for overweight/obesity and poor physical activity inequalities were explained by wealth status itself. However the contribution of wealth status for poor physical activity was negative implying the concentration among the poor.

\section{Strengths and limitations}

The main limitation of this study is that NCD risk factors were based on self-reports. However since our study applies a standard chronic disease risk surveillance approach (WHO STEPs) the findings can be comparable to those from other setttings and countries. Since the NCD study 
sample was not designed to be representative of Botswana, a caution should be taken while generalizing these study findings.

\section{Conclusions}

Overall the study showed mixed findings on the association between SES and NCD risk factors. It was noted that the poor were more likely to be exposed to some NCD risk factors than the non-poor and vice versa. For instance, smoking, poor physical activity, and poor fruit and vegetable were observed to be more concentrated among the poor, while alcohol consumption was found to be concentrated among the non-poor. These results demonstrate that socioeconomic factors play an important role in prevalence of NCD risk factors in Botswana. The recently introduced Botswana's multisectoral national strategic plan implementation framework for combating NCDs (2017-2022) should focus on developing a socioeconomic status based awareness about the harmful impact of smoking, alcohol, physically inactivity and poor quality of diet facilited by comprehensive national monitoring and evaluvation framework. Considering high levels of smoking and poor fruit and vegetable consumption among the poor there is need for enhanced education on the long term effects of these risk factors. Similarly the non-poor need to be encouraged to adopt healthy diets and exercise regularly.

\section{Additional files}

Additional file 1: Methodology for the NCDs study,2016 (Chapter 3) (DOCX $135 \mathrm{~kb}$ )

Additional file 2: Questionnaires (DOCX $68 \mathrm{~kb}$ )

Additional file 3: Decomposition analysis equation (DOCX $23 \mathrm{~kb}$ )

\section{Abbreviations}

AOR: Adjusted Odd Ratios; Cl: Confidence Interval; NCD: Non-Communicable Diseases; SES: Socioeconomic Status; WHO: World Health Organization

\section{Acknowledgements}

The authors wish to thank Office of Research and Development (ORD) at University of Botswana for providing the funding for the study. Furthermore the authors wish to thank the Department of Population Studies for providing resources to conduct the analysis of data for the study.

\section{Authors' contributions}

MK conceived the study, did the analysis and wrote the first draft of the manuscript. KN, GL, and SDR reviewed the manuscript and provided critical comments on its improvement. All authors read and approved the final manuscript.

\section{Funding}

The funding for the study was provided for by the Office of Research and Development (ORD) at University of Botswana during the Round 28 funding. Meanwhile, the ORD did not have any part in the design of the study and collection, analysis, and interpretation of data and in writing this manuscript.The ORD only provided core funding for the NCDs survey.

\section{Availability of data and materials}

Study materials and de-identified data that support the findings in this study may be obtained from Mpho Keetile on reasonable request through permission from the Office of Research and Development,University of Botswana.

\section{Ethics approval and consent to participate}

The study proposal along with the survey instruments were submitted to and approved by the Institutional Review Board of the University of Botswana (Ref \#: UBR/RES/RB/1583) for ethical clearance. Ethical clearance and research permit were also obtained from the Government of Botswana through the Ministry of Health and Wellness (Ref \#: HPDME: 13/18/1 Vol. X (130). Informed written consent was sought from all eligible participants before the interviews. Privacy and confidentiality of the highest standard was maintained throughout the study by keeping the respondents anonymous.

\section{Consent for publication}

Not applicable.

\section{Competing interests}

The authors declare that they have no competing interests.

Received: 29 January 2019 Accepted: 30 July 2019

Published online: 07 August 2019

\section{References}

1. WHO, Commission on Social Determinants of Health - final report. (2008) https://www.who.int/social_determinants/thecommission/finalreport/en/.

2. WHO. Closing the gap: policy into practice on social determinants of health, world conference on social determinants of health, vol. Discussion paper. Rio de Janeiro: WHO; 2011. p. 56.

3. Clougherty JE, Souza K, Cullen MR. Work and its role in shaping the social gradient in health. Ann N Y Acad Sci. 2010;1186:102-24.

4. Hämmig O, Bauer GF. The social gradient in work and health: a crosssectional study exploring the relationship between working conditions and health inequalities. BMC Public Health. 2013;13:1170. https://doi.org/10.11 86/1471-2458-13-1170

5. Bendaoud ML, Callens S. Psychological and social factors of health inequalities. New health systems; integrated care and health inequalities reduction; 2017. p. 19-63.

6. Schäfer I, von Leitner EC, Schön G, Koller D, Hansen H, Kolonko T, Kaduszkiewicz H, Wegscheider K, Glaeske G, van den Bussche H. Multimorbidity patterns in the elderly: a new approach of disease clustering identifies complex interrelations between chronic conditions. PLoS One. 2010;5:e15941. https://doi.org/10.1371/journal.pone.0015941.

7. Niessen LW, Mohan D, Akuoku JK. Tackling socioeconomic inequalities and non-communicable diseases in low-income and middle-income countries under the sustainable. Lancet. 2018;391:2036-204.

8. Farrell C, McAvoy H. Wilde, J. and combat poverty agency. Tackling health inequalities - an all-Ireland approach to social determinants. Dublin: Combat Poverty Agency/Institute of Public Health in Ireland; 2008.

9. Ginsburg C, Griffiths PL, Richter LM, Norris SA. Residential mobility, socioeconomic context and body mass index in a cohort of urban south African adolescents. Health Place. 2013;19(100):99-107.

10. Khan JA, Trujillo AJ, Ahmed S, Siddique AT, Alam N, Mirelman AJ, Koehlmoos TP, Niessen LW, et al. Distribution of chronic disease mortality and deterioration in household socioeconomic status in rural Bangladesh: an analysis over a 24-year period. Int J Epidemiol. 2015;44(6):1917-26.

11. Chandola T, Clarke P, Morris J, Blane D. Pathways between education and health: a causal modelling approach. J R Stat Soc A. 2006;169(2):337-59.

12. Yu Y, Sloan FA. Trends in elderly health by cohort: evidence from China. China Econ Rev. 2017:44:282-95.

13. Xu Z, Brown LM, Pan GW, Liu TF, Gao GS, Stone BJ, et al. Cancer risks among iron and steel workers in Anshan, China, part II: case-control studies of lung and stomach cancer. Am J Ind Med. 1996;30:7-15 pmid:8837676.

14. Fan AZ, Strasser SM, Zhang X, Fang J, Crawford CG. State socioeconomic indicators and self-reportedhypertension among US adults, 2011 behavioral risk factor surveillance system. Prev Chronic Dis. 2015;12140353. https://doi. org $/ 10.5888 /$ pcd 12.140353

15. Enoch MA. The role of early life stress as a predictor for alcohol and drug dependence. Psychopharmacology (Berl). 2011;214(1):17-31. https://doi. org/10.1007/s00213-010-1916-6 
16. Yusuf S, Rangarajan S, Teo K, Islam S, Li W, Liu L, et al. PURE investigators. Cardiovascular risk and events in 17 low-, middle-, and high-income countries. N Engl J Med. 2014;371(9):818-27. https://doi.org/10.1056/ NEJMoa1311890.

17. Smith GD, Hart C, Watt DG, Hole D, Hawthorne V. Individual social class, area-based deprivation, cardiovascular disease risk factors and mortality: the Renfrew and Paisley study. J Epidemiol Community Health. 1998;52:399-402.

18. McCartney G, Collins C, Mackenzie M. What (who) causes health inequalities: theories, evidence and implications? Health Policy. 2013;113:221-7.

19. McLaren L. Socioeconomic status and obesity. Epidemiol Rev. 2007;29:2948. https://doi.org/10.1093/epirev/mxm001.

20. Laaksonen M, Rahkonen O, Karvonen S, Lahelma E. Socio-economic status and smoking: Analysing inequalities with multiple indicators. Eur J Pub Health. 2005;15:262-9.

21. Peltzer K, Pengpid S, Samuels TA, Özcan NK, Mantilla C, Rahamefy OH, Wong ML, Gasparishvili A. Prevalence of overweight and obesity and its associated factors among university students from 22 countries. Int J Environ Res Public Health. 2014;11(7):7425-41. https://doi.org/10.3390/ ijerph110707425.

22. Blakely $T$, Hunt D, Woodward A. by socio-economic position remains after adjusting for neighbourhood deprivation: an example using smoking and mortality. J Epidemiol Community Health. 2005;58(12):1030-1.

23. Allen L, Williams J, Townsend N. Socioeconomic status and non-communicable disease behavioural risk factors in low-income and lower-middle-income countries: a systematic review. Lancet Glob Health. 2017;5:e277-89.

24. Aryal KK, Mehata S, Neupane S, Vaidya A, Dhimal M, Dhakal P, et al. The burden and determinants of non communicable diseases RiskFactors in Nepal: findings from a Nationwide STEPSSurvey. PLoS One. 2015;10(8): e0134834. https://doi.org/10.1371/journal.pone.0134834.

25. Ministry of Health and World Health Organization. Botswana chronic disease risk factor surveillance report 2007. Gaborone: Ministry of Health, DPH, disease control division; 2007. https://www.who.int/ncds/surveillance/ steps/2007_STEPS_Report_Botswana.pdf.

26. World Health Organization. Food and agriculture organization. Diet, nutrition and the prevention of chronic diseases. (Report of a Joint WHO/ FAO Expert Consultation). Geneva: WHO; 2003.

27. World Health Organization. WHO STEPwise approach to chronic disease risk-factor surveillance: the WHO STEPS surveillance manual. Geneva; 2011. http://www.who.int/chp/steps/manual/en/index.html.

28. Wagstaff A, Bilge M, Sajaia Z, Lokshin M. Health equity and financial protection:streamlined analysis with ADePT software. Washington DC: World Bank; 2011.

29. Wagstaff A, Van Doorslaer E. Catastrophe and impoverishment in paying for health care: with applications to Vietnam 1993-1998. Health Econ. 2002; 12(11):921-34.

30. Wagstaff A, Paci P, van Doorslaer E. On the measurement of health inequalities in health. Soc Sci Med. 1991;33:545-57.

31. Regidor E. Measures of health inequalities: part 2. J Epidemiol Community Health. 2004;58:900-3.

32. Vyas S, Kumaranayake L. Constructing socio-economic status indices: how to use principal components analysis. Health Policy Plan. 2006;21:459-68.

33. Gwatkin DR, Rutstein S, Johnson K, Suliman E, Wagstaff A, Amouzou A. Socio-economic differences in health, nutrition, and population within developing countries: an overview. Niger J Clin Pract. 2007;10:272-82.

34. Clarke PM, Gerdtham UG, Connelly LB. A note on the decomposition of the health concentration index. Health Econ. 2003;12:511-6.

35. Weiser SD, Karen L, Heisler M, McFarland W, Percy-de Korte F, DeMonner $\mathrm{SM}$, et al. A population-based study on Alcoholand high-risk sexual behaviors in Botswana. PLoS Med. 2006;3(10).

36. Sommer I, Griebler U, Mahlknecht P, Thaler K, Bouskill K, Gartlehner G, Mendis S. Socioeconomic inequalities in non-communicable diseases and their risk factors: an overview of systematic reviews. BMC Public Health. 2015;15:914.

37. Karriker-Jaffe KJ, Zemore SE, Mulia N. Neighborhood disadvantage and adult alcohol outcomes: differential risk by race and gender. J Stud Alcohol Drugs. 2012;73(6):865-73.

38. Collins SE. Associations between socioeconomic factors and alcohol outcomes. Alcohol Res. 2016;38(1):83-94.

39. Setshegetso N. Food consumption changes in Botswana since 1966. PULA: Botswana. J Afr Stud. 2017;31(2):87-94.
40. Appelhans BM, Milliron B-J, Woolf K, Johnson TJ, Pagoto SL, Schneider KL, Whited MC, Ventrelle JC. Socioeconomic status, energy cost, and nutrient content of supermarket food purchases. Am J Prev Med. 2012;42:398-402.

41. Pechey $\mathrm{R}$, Jebb SA, Kelly MP, Almiron-Roig E, Conde S, Nakamura R, Shemilt I, Suhrcke M, Marteau TM. Socioeconomic differences in purchases of more vs. less healthy foods and beverages: analysis of over 25,000 British households in 2010. Soc Sci Med. 2013;92:22-6.

42. Aggarwal A, Monsivais P, Cook AJ, Drewnowski Aizuddin A, N A, Zainuddin Z, Manaf MRA. Does diet cost mediate the relation between socioeconomic position and diet quality? Eur J Clin Nutr. 2011;65:1059-66.

43. Hosseinpoor AR, Parker LA, Tursand'Espaignet E, Chatterii S. Socioeconomic inequality in smoking in low-income and middle-income countries: results from the world health survey. PLoS One. 2012;7(8):e42843.

44. Huisman M, Kunst AE, Mackenbach JP. Socioeconomic inequalities in morbidity among the elderly; a European overview. Soc Sci Med. 2003; 57(5):861-73.

45. Jeremias E, Chatkin JM, Chatkin G, Seibert J, Martins M, Wagner M. Smoking cessation in older adults. Int J Tuberc Lung Dis. 2012;16:273-8.

46. Link BG, Phelan J. Social conditions as fundamental causes of disease. J Health Soc Behav Spec. 1995:45:80-94.

\section{Publisher's Note}

Springer Nature remains neutral with regard to jurisdictional claims in published maps and institutional affiliations.

\section{Ready to submit your research? Choose BMC and benefit from:}

- fast, convenient online submission

- thorough peer review by experienced researchers in your field

- rapid publication on acceptance

- support for research data, including large and complex data types

- gold Open Access which fosters wider collaboration and increased citations

- maximum visibility for your research: over $100 \mathrm{M}$ website views per year

At BMC, research is always in progress.

Learn more biomedcentral.com/submissions 